\title{
UMA EXPERIÊNCIA DE PÓS-DOUTORADO EM ENFERMAGEM NO BRASIL *
}

\author{
Celma Marfins Guimarães ** \\ Semiramis Melani Meio Rocha ***
}

\section{INTRODUÇÃO}

Um programa de pós-doutorado, financiado pelo Conselho Nacional de Desenvolvimento Científico e Tecnológico (CNPq), tem por objetivo estimular doutores e docentes pesquisadores a realizarem estágios para consolidação e atualização de seus conhecimentos, campos definidos de interesse científico e tecnológico. São requisitos para a instituição que oferece o programa, possuir quadro de docentes pesquisadores/doutores de alta qualificação e desempenho científico notável.

O pós-doutorado tem sido realizado mais comumente no exterior, entretanto, pode e deve ser incentivado no país, com a finalidade de promover o

intercâmbio institucional e entre pesquisadores, aprimorando e aprofundando a pesquisa e o ensino, formando núcleos de investigação articulados a pólos já consolidados.

Este trabalho tem por objetivo descrever a primeira experiência de um programa de Pós-Doutorado em Enfermagem realizado no Brasil e refletir sobre a possibilidade de sua reprodução no País e na América Latina.

\section{ETAPAS DO PROCESSO DE FORMALIZAÇÃO DO PROGRAMA}

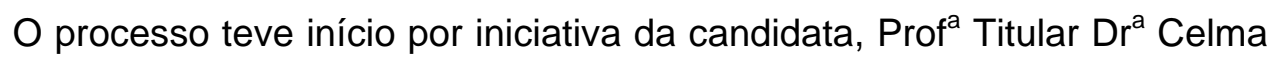
Martins Guimarães, docente da Universidade Federal de Goiás e Universidade Católica de Goiás, solicitando à Escola de Enfermagem de Ribeirão Preto (EERP) da Universidade de São Paulo (USP) a realização do pós-doutorado, em 21 de fevereiro de 1992. Apresentou um projeto cujos objetivos eram:

- desenvolver um projeto de pesquisa intitulado "A Enfermagem como Prática Social: determinantes sócio-históricos e engajamento profissional";

- promover a implantação de cursos de pós-graduação (especialização e mestrado) em enfermagem em Goiânia;

- participar de forma ativa de encontros realizados nas áreas de enfermagem e saúde coletiva.

\footnotetext{
* Programa de Pós-Doutorado em Enfermagem do Departamento Materno-Infantil e Saúde Pública da Escola de Enfermagem de Ribeirão Preto da Universidade de São Paulo

** Pós-Doutoranda, Faculdade de Enfermagem e Nutrição, Departamento de Enfermagem, MEC-UFG e Universidade Católica de Goiás

*** Tutora, Departamento de Enfermagem Materno-Infantil e Saúde Pública da Escola de Enfermagem de Ribeirão Preto da Universidade de São Paulo
} 
A solicitação foi encaminhada ao Departamento de Enfermagem MatemoInfantil e Saúde Pública, em decorrência da área de conhecimento e linha de pesquisa em que o projeto se inseria. O Conselho do Departamento, então presidido pela Prof $^{a} D^{a}$ Maria Cecíllia Puntel de Almeida, promoveu uma ampla discussão entre os docentes e a candidata, a fim de organizar um programa de estudos e indicar docentes responsáveis. Em reunião de 12 de maio de 1992, o Conselho do Departamento manifestou-se favorável à oferecer o estágio, estabelecendo condições e atividades a serem desenvolvidas, designando como tutora da Pós-Doutoranda, a Prof ${ }^{\mathrm{a}} \mathrm{D}^{\mathrm{a}}$ Semiramis Melani Melo Rocha.

Inicialmente, foi estabelecida a duração de um ano, contada a partir de agosto de 1992, posteriormente prorrogada, com término previsto para agosto de 1994. A programação incluía atividades didáticas, o desenvolvimento do projeto de pesquisa, que foi sendo re-elaborado no decorrer do trabalho e a participação no Núcleo de Pesquisa e Estudos em Saúde Coletiva (NUPESCO) do Departamento de Enfermagem Materno-Infantil e Saúde Pública (MISP). A experiência da Prof ${ }^{a}$ $D^{a}$ Marli Villela Mamede, com Pós-Doutorado na Universidade de Illinois nos Estados Unidos, muito contribuiu para a organização da proposta.

Não foi solicitado o financiamento do Programa em sua primeira fase. No período compreendido entre abril de 1993 e outubro de 1994, a Pós-Doutoranda recebeu subsídios financeiros do CNPq, cumprindo as determinações desta agência de fomento, para o caso.

\section{DESENVOLVIMENTO DO PROGRAMA}

A atividade central foi um trabalho de investigação intitulado "A PósGraduação stricto sensu em Saúde Coletiva no Brasil e os programas de pósgraduação em Enfermagem nesta área do conhecimento" tendo por objetivos:

- analisar as características dos cursos de pós-graduação que fazem parte dos "Catálogos de Pós-Graduação em Saúde Coletiva - Brasil" (19831993), publicados pela Associação Brasileira de Pós-Graduação em Saúde Coletiva (ABRASCO), no que se refere à localização, denominação, áreas de concentração, clientela, seleção, número de vagas, duração, objetivos e estrutura curricular;

- apreender os determinantes sociais, políticos e econômicos das modificações na estrutura curricular, enfatizando as transformações nas políticas de saúde;

- estudar os cursos de pós-graduação em enfermagem na área de saúde coletiva.

Esta investigação teve por finalidade subsidiar um projeto de implantação de um curso de mestrado em Saúde Coletiva, multiprofissional, na Região Centro-Oeste do País.

Em decorrência desta proposta, a pós-doutoranda vinculou-se ao Núcleo de Pesquisa e Estudos em Saúde Coletiva (NUPESCO), que tem por finalidade realizar estudos avançados em teoria do conhecimento, métodos e técnicas de investigação em saúde coletiva, estudar as políticas e o processo de trabalho em saúde.

Em um estágio de pós-doutorado busca-se o envolvimento do pesquisador com a instituição formadora e com as atividades que ela desempenha, principalmente em nível de pós-graduação, permitindo que leve 
para a instituição de origem, informações e experiências vivenciadas. Para tanto, o programa constou de:

- participação em disciplinas de pós-graduação, relacionadas a área de conhecimento em questão, em atividades docentes e discentes;

- participação em pesquisas em andamento e divulgação das mesmas em eventos e publicações;

- participação em organização de eventos, grupos de estudos e procedimentos administrativos;

- elaboração de relatórios (semestrais) de atividades desenvolvidas;

- abertura de canais de comunicação com outros Departamentos, outras Unidades do Campus, setores de apoio como bibliotecas, laboratórios, recursos audio-visuais, entre outros.

O que se pretendeu foi estruturar um Programa que articulasse atividades de ensino e pesquisa, possibilitando a ampla participação da pós-doutoranda nos programas e atividades desenvolvidos pelo Departamento (MISP) e Núcleo de Pesquisa e Estudos em Saúde Coletiva.

Em contra-partida, a presença de um docente de outra instituição no Departamento que recebe o pós-doutorando enriquece o ensino e a pesquisa através do intercâmbio de idéias, vivências, conhecimentos.

Em 14 de outubro de 1994 foram entregues ao Departamento de Enfermagem Materno-Infantil e Saúde Pública da EERP-USP, o relatório final das atividades desenvolvidas e o trabalho de investigação. Com a aprovação dos mesmos, foi realizada em 17 de março de 1995, em sessão solene, a entrega do título à pós-doutoranda.

O elo criado está sendo mantido e há expectativas de continuidade e aprofundamento.

\section{CONSIDERAÇÕES FINAIS}

No conjunto das áreas de conhecimento que formam recursos humanos em centros qualificados no País e no exterior, para pesquisa e docência universitária, a enfermagem ainda é considerada uma área nova e em processo de consolidação de suas linhas de pesquisa. A demanda aos órgãos de fomento é muito pequena quando comparada a outras, cujos pesquisadores afluem com maior número de solicitações. Várias hipóteses para justificativa tem sido levantadas, como por exemplo, a predominância de mulheres na profissão, a dificuldade no domínio de língua estrangeira, entre outras.

O pós-doutorado no Brasil, oferecido por centros com núcleos de pesquisa consolidados é uma experiência que pode proporcionar o avanço de conhecimento, a capacitação científica e tecnológica, visando a aplicação dos resultados em setores sociais que muito se beneficiariam. Neste caso específico, a enfermagem poderia contribuir para a qualificação da assistência no setor saúde. Para estes núcleos, o intercâmbio com pesquisadores já formados proporciona uma diversificação e difusão de informações.

No nosso ponto de vista, como pós-doutoranda e tutora do programa, a experiência foi bastante profícua, o que nos motivou a relatá-la, visando promover sua continuidade e ampliação. 